\section{Electronic cigarettes: pro}

\author{
John Britton
}

Smoking destroys lives, and does so from the point of conception. In 2014 smoking is likely to have caused the death of over 5000 unborn or newly born babies, over 20000 babies to be born prematurely or with low birth weight, 40 sudden infant deaths and over 165000 new cases of childhood illness. ${ }^{1}$ Smoking in England alone will have killed around 80000 adults, ${ }^{2}$ caused nearly 500000 admissions to National Health Service (NHS) hospitals ${ }^{2}$ and consumed around $£ 5$ billion of the NHS budget. ${ }^{3}$ The total financial cost of smoking to wider society will have been nearly $£ 14$ billion, ${ }^{3} £ 4$ billion more than the tax that tobacco generates ${ }^{3}$ and around $15 \%$ of the current UK national budget deficit. ${ }^{4}$ Adult smoking will also have exacerbated adult and child poverty, and contributed to initiating the next generation of children into smoking. ${ }^{5}$ These health and social effects identify smoking as by far the largest avoidable cause of death and disability in the UK. Preventing smoking should therefore be the first priority of health and social policy.

The UK leads Europe in implementing tobacco control policy, ${ }^{6}$ and has achieved a profound reduction in the prevalence of smoking among adults, which in 2013 fell below $20 \%$ for the first time in nearly a century. ${ }^{7}$ However this prevalence figure translates into around 10 million UK adults alive today who smoke, and of whom half will die from their smoking unless they can be persuaded and helped to quit. ${ }^{8}$ The headline success in reducing smoking prevalence is also not universal across society, since smoking remains twice as common among people in unskilled and manual occupations than in professional and managerial groups, ${ }^{2}$ and much higher still among the unemployed, the homeless, in prisoners and other severely disadvantaged groups. ${ }^{9}$ Among people with mental health problems the prevalence of smoking remains at around $40 \%$, and has barely changed in the last 20 years. $^{9}$ Persevering with conventional tobacco control policies may well eventually gradually eradicate smoking across society, but will take decades to do so. We urgently need innovations to complement these approaches

Correspondence to Professor John Britton, UK Centre for Tobacco and Alcohol Studies, University of Nottingham, Nottingham NG5 1PB, UK; j.britton@virgin.net and reduce the prevalence of current smoking significantly more substantially, and as quickly as possible.

Electronic cigarettes have the potential to do this. ${ }^{10}$ Smokers smoke because they are addicted to nicotine, but nicotine is not itself a significant hazard to health: ${ }^{11}$ the harm from smoking is caused primarily by the thousands of other toxins in smoke. $^{12}$ Whereas conventional tobacco control approaches aim to help smokers to quit smoking and all nicotine use, electronic cigarettes offer the alternative of continuing to inhale nicotine but without most of the toxicity of tobacco smoke. Electronic cigarettes vary substantially in quality, nicotine delivery and levels of contaminants in the vapour they produce but most deliver nicotine in a carrier, usually propylene glycol, with variable degrees of contamination by impurities from the nicotine solution or generated by vapour production. ${ }^{10} 13$ Electronic cigarettes are not safe therefore, and the hazards of long-term use will remain unknown for decades, but are likely to be of orders of magnitude substantially lower than those of smoking. ${ }^{10} 12$ Therefore, for smokers unable or unwilling to quit all tobacco and nicotine use, or who find medicinal nicotine preparations unsatisfactory as a smoking substitute, switching to electronic cigarettes is the next best option for health. Use by never-smokers, on the other hand, although unlikely to cause major harm, is best avoided.

Proof of concept of a harm reduction approach is demonstrated in Sweden, where the use of oral tobacco, known as snus, has contributed to a smoking prevalence that is by far the lowest in Europe. ${ }^{12}{ }^{14}$ However, while snus is not an option for UK smokers, being illegal in the UK and the wider European Union, it appears that electronic cigarettes are being used in the UK in a similar way to snus in Sweden. Recent data suggest that around $12 \%$ of adult smokers also use electronic cigarettes, and that just under $5 \%$ of smokers-500 000 people-appear to be exclusive electronic cigarette users. ${ }^{7}$ Use of electronic cigarettes by young people who do not smoke appears to be rare. ${ }^{15} 16$ Electronic cigarettes appear to be being used primarily by people who do not access conventional smoking cessation services, ${ }^{17}$ and by engaging this group in cessation activity seems that electronic cigarettes are helping to reduce the prevalence of smoking. ${ }^{17}$ With appropriate regulation and close monitoring of patterns of use it is therefore possible that electronic cigarettes and related products could in the future play a significant part in eradicating tobacco smoking from the UK.

Any health intervention comes at a price and in the case of a powerful but largely untested and to date relatively unregulated technology such as this, there are significant potential risks. These risks, and other arguments used against electronic cigarettes are summarised below, with a response to them:

1. They perpetuate addiction: Preventing addiction is not the prime objective of health policy (if it were, we would be trying to eradicate tea and coffee drinking); the prime objective is to prevent harm. The same argument also applies to, but is not used against, licensed nicotine replacement therapy.

2. The health risks of electronic cigarettes are unknown: This is true, but they are clearly orders of magnitude less severe than those of smoking. ${ }^{10} 12$

3. Electronic cigarettes are not safe: This is also true, but neither are many, or indeed most, medical therapies. Electronic cigarettes are however much less hazardous than smoking.

4. Vapour may harm others: This is theoretically possible, but practically unlikely as the vapour contains little of potential hazard and has a half-life of seconds. ${ }^{18}$ It is a matter of courtesy however not to use electronic cigarettes in a manner that causes other people to be exposed involuntarily.

5. Products standards vary: There is an urgent need for regulation to ensure that electronic cigarettes deliver nicotine without unnecessary hazard.

6. There are few clinical trials demonstrating cessation efficacy: The Medicines and Healthcare Regulatory Agency (MHRA) considers products that deliver nicotine to be effective smoking cessation aids, and so do not require clinical trial evidence of efficacy necessary. ${ }^{19}$

7. Smokers may dual use: This is encouraged with Nicotine Replacement Therapy, which is licensed for dual use.

8. They will 'renormalise' smoking: There is no evidence that this is happening.

9. They will be promoted to nonsmokers: Advertising regulation is needed to prevent this.

10. They are a gateway to smoking: There is no evidence that this is happening in the UK. If it were, it would be a 
concern only if electronic cigarette use among young people resulted in more, rather than less, young people taking up smoking.

11. They are a fire risk if used with the wrong charger: This applies to all electrical appliances with batteries. Use the right charger.

12. They are cannibalising NHS Stop Smoking Service (SSS) uptake: This may be true, to a degree. The solution is for SSS to embrace, not reject, the potential of these products and thus support smokers who are using electronic cigarettes to try to quit.

13. The manufacturers can't be trusted: Regulation of advertising and product standards are urgently needed.

14. The tobacco industry is now involved in the electronic cigarette market: This is a cause for concern, but the primary target of tobacco control is to prevent smoking. If the tobacco industry produces products that are an effective harm reduction option, we should be prepared to use them.

15. Smoking is declining without electronic cigarettes: True, but not quickly enough, and certainly not in disadvantaged groups. These smokers need all the help they can get to quit smoking as soon as possible.

16. Smokers can use NHS SSS to quit: Sadly, less than $10 \%$ do. We need more options for the majority who don't.

17. Smokers should use NHS SSS: This is a 'quit or die' logic. Electronic cigarettes offer an alternative.

18. We didn't think of them: Not all great ideas in medicine come from doctors.

There are other arguments not presented above, and more will arise, but in my view electronic cigarettes represent a potent opportunity to prevent death and disability from smoking. It is therefore important to grasp the opportunity they provide while also managing the risks to minimise any unwanted effects. I therefore propose that electronic cigarettes are an opportunity that health professionals should welcome and develop, and use them to help prevent death and disability from smoking in our society.

\section{Competing interests None.}

Provenance and peer review Not commissioned; internally peer reviewed.

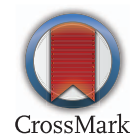

To cite Britton J. Thorax 2015;70:309-310.

Accepted 13 February 2015

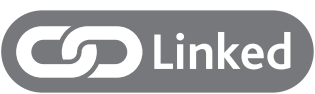

- http://dx.doi.org/10.1136/thoraxjnl-2014-206735

Thorax 2015;70:309-310.

doi:10.1136/thoraxjnl-2015-206935

\section{REFERENCES}

1 Royal College of Physicians. Passive smoking and children. A report by the Tobacco Advisory Group of the Royal College of Physicians. London: RCP; 2010. http://www.rcplondon.ac.uk/sites/default/files/ documents/passive-smoking-and-children.pdf

2 Health and Social Care Information Centre. Statistics on Smoking, England-2014. Health and Social Care Information Centre, 2014. http://www.hscic.gov. uk/catalogue/PUB14988/smok-eng-2014-rep.pdf

3 Allender S, Balakrishnan R, Scarborough P, et al. The burden of smoking-related ill health in the UK. Tobacco Control 2009;18:262-7.

4 Office for Budget Responsibility. Economic and fiscal outlook December 2014. Office for Budget Responsibility. 2014. http://cdn.budgetresponsibility. independent.gov.uk/December_2014_EFO-web513.pdf

5 Leonardi-Bee J, Jere ML, Britton J. Exposure to parental and sibling smoking and the risk of smoking uptake in childhood and adolescence: a systematic review and meta-analysis. Thorax 2011;66:847-55.

6 Joossens L, Raw M. The tobacco control scale 2013 in Europe. Brussels: Association of European Cancer Leagues, 2014. http://www.europeancancerleagues. org/images/TobaccoControl/TCS_2013_in_Europe 13-03-14_final_1.pdf

7 Office for National Statistics. Adult smoking habits in Great Britain, 2013. Office for National Statistics,
2014. http://www.ons.gov.uk/ons/dcp171778 386291.pdf

8 Doll R, Peto R, Boreham J, et al. Mortality in relation to smoking: 50 years' observations on male British doctors. Br Med J 2004;328:1519-33.

9 Royal College of Physicians, Royal College of Psychiatrists. Smoking and mental health. London: RCP; 2013. http://www.rcplondon.ac.uk/sites/default/files/ smoking_and_mental_health_-_full_report_web.pdf

10 Britton J, Bogdanovica I. Electronic cigarettes. A report commissioned by Public Health England. Public Health England, 2014 https://www.gov.uk/ government/uploads/system/uploads/attachment_ data/file/311493/Ecigarettes_report.pdf; (accessed 15 May 2014).

11 National Institute for Health and Care Excellence. Tobacco-harm reduction approaches to smoking: Evidence reviews. NICE, 2013. http://www.nice.org. uk/nicemedia/live/14178/64034/64034.pdf (accessed 12 Jun 2013).

12 Tobacco Advisory Group of the Royal College of Physicians. Harm reduction in nicotine addiction. London: Royal College of Physicians. 2007. http:// www.rcplondon.ac.uk/sites/default/files/documents/ harm-reduction-nicotine-addiction.pdf

13 Pisinger C, Dossing M. A systematic review of health effects of electronic cigarettes. Prev Med 2014;69C:248-60.

14 Scientific Committee on Emerging and Newly Identified Health Risks. Health effects of smokeless tobacco products. European Commission, 2008.

15 Action on Smoking and Health. Use of electronic cigarettes in Great Britain. Action on Smoking and Health, 2014. http://www.ash.org.uk/files/documents/ ASH_891.pdf (accessed 13 Aug 2014)

16 Scottish Schools Adolescent Lifestyle and Substance Use Survey. Smoking among 13 and 15 year olds in Scotland 2013. NHS National Services Scotland, 2014. http://www.isdscotland.org/Health-Topics/ Public-Health/Publications/2014-11-25/SALSUS_ 2013 Smoking_Report.pdf

17 Smoking Toolkit Study. STS1401222 Electronic cigarettes in England-latest trends. Smoking in England, 2014. http://www.smokinginengland.info/ latest-statistics/

18 Bertholon JF, Becquemin MH, Roy $\mathrm{M}$, et al. Comparison of the aerosol produced by electronic cigarettes with conventional cigarettes and the shisha. Rev Mal Respir 2013;30:752-7.

19 Medicines and Healthcare products Regulatory Agency. Licensing Procedure for Electronic Cigarettes and Other Nicotine Containing Products (NCPS) as Medicines. Medicines and Healthcare Products Regulatory Agency Committee on Safety of Medicines. 2014. http://www.mhra.gov.uk/home/ groups/comms-ic/documents/websiteresources/ con454361.pdf (accessed 9 Dec 2014). 